\title{
Use of Silimarin in the Treatment of Non-Alcoholic Fatty Liver Disease (Nafld)
}

Sander BQ*, Barcellos HB, Barbosa ERA, Oeiras CR, Veríssimo AR, Oliveira FEM, Dantas LC, Marques JMG, Oliveira REM, Portela E, Sindorf ML, Rezende FA, Sena WR, Moura TA, Rodrigues IW, Mendonça Filho PRR, Rocha GG, Chalita HGJ, Silva JA, Andreatta MFS, Coelho AT and Pereira CRT

Sander Medical Center, Brazil

*Corresponding author: Sander BQ Sander Medical Center, Brazil.

Received Date: June 30, 2021

Published Date: July 15, 2021

\section{Introduction}

Non-alcoholic hepatic steatosis is characterized by steatosis and necroinflammation, with or without centrilobular fibrosis [1], in cases where the deposit of lipids in hepatocytes exceeds $5 \%$ of the total weight of the liver and there is no other causes of hepatic involvement [2]. Therefore, in its diagnosis it is necessary to exclude viral hepatitis, use of drugs that promote parenchymal alterations, autoimmune hepatitis, hemochromatosis, Wilson's disease, or significant alcohol consumption above $30 \mathrm{~g}$ daily for men, and 20 $\mathrm{g}$ daily for women [3]. The main risk factors for its development are the components of the metabolic syndrome, weight gain, insulin resistance, hypertension, and hyperlipidemia [1]. These risk factors suggest reasons for the increased prevalence of nonalcoholic hepatic steatosis in the world, probably as a result of changes in lifestyle and eating habits, with increasing consumption of carbohydrates, also contributing to the evolution of diagnostic methods for the disease. This prevalence, although the numbers may vary between authors, is currently estimated at $20 \%$ to $40 \%$ in the world population, and this high incidence has become a source of concern for health professionals [3-6].

Along with the epidemiological importance, there is also the progressive and sometimes severe character of the disease evolution, which varies from chronic hepatitis and liver cirrhosis, even to hepatocellular carcinoma [6, 7]. In addition, such as hepatic steatosis Non-alcoholic is a simpler component of non-alcoholic fatty liver disease (NAFLD), this broad evolutionary spectrum may indicate that this disease precedes and often signals the development of other diseases such as cardiovascular diseases, hypertension, and type 2 diabetes mellitus, thus being associated with an increase in mortality [8]. Studies on the diagnosis of the disease show that most patients are asymptomatic, while others have nonspecific symptoms, such as fatigue and right upper quadrant pain. There are no typical characteristics on physical examination, although central obesity and hepatomegaly are common, even if mild [2]. Among the most accurate diagnostic methods are invasive tests, and liver biopsy is currently considered the "gold standard" in these cases [9].

As for non-invasive methods, they are important means for early diagnosis in asymptomatic patients, as well as to help and identify patients at higher risk of developing the disease's evolutionary forms, as the high prevalence of NAFLD makes it impractical to perform biopsies in all patients [9]. Among these methods, ultrasound is the most practical and simple, and therefore the first option for diagnosis, mainly because it does not use ionizing radiation, is inexpensive, more accessible and has no side effects [10]. Nuclear magnetic resonance (NMR), on the other hand, is considered the most effective non-invasive method for diagnosing this condition, but it is still an expensive procedure and still inaccessible [11]. For the treatment of the disease, it is recommended from changing the lifestyle, with regular practice of aerobic physical activity associated with dietary re-education in a guided way, to the use of medication, being essential to control the associated metabolic comorbidities, such as obesity, dyslipidemia, insulin resistance and type 211 diabetes mellitus. 
As for drug treatment, only a limited number of studies have demonstrated any efficacy in interventions with pharmacological and dietary supplements in non-alcoholic hepatic steatosis, and so far there is no approved pharmacological agent for the specific treatment of this condition [1]. Some studies also show modest improvements in the use of some drugs, from the analysis of liver function markers, such as transaminases, and from the histological analysis of slides obtained from biopsies, liver function tests and even histological parameters. However, such studies had small samples and short follow-up periods $[1,11]$. Treatments with natural substances have been proposed and the most researched of them for liver disorders is made using silymarin [12] (Figure 1). A compound used for centuries to treat liver, spleen, and gallbladder disorders, due to its hepatoprotective, anti-inflammatory, antiproliferative, immunomodulatory and anticholesterolemic [1315] properties, silymarin is a substrate extracted from the plant Silybum marianum (or milk thistle). In it, silybin, identified as a biologically active component, is responsible for $50 \%$ to $70 \%$ of its composition [14] (Figure 2).

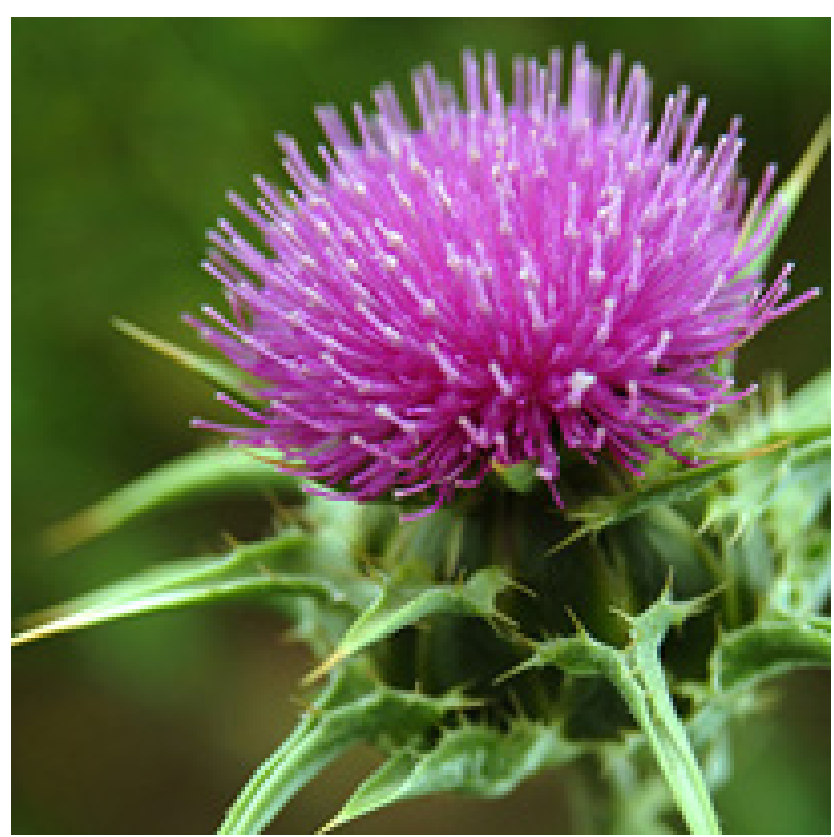

Figure 1: Planta Silybum marianum.<smiles>COc1cc(C2Oc3cc(C4Oc5cc(O)cc(O)c5C(=O)C4O)ccc3OC2CO)ccc1C</smiles>

Silibina<smiles>COc1cc(C2OC3=C(O)CC(C4Oc5cc(O)cc(O)c5C(O)C4O)C=C3C2CO)ccc1O</smiles>

Silicristina<smiles>COc1cc(C2Oc3ccc(C4Oc5cc(O)cc(O)c5C(=O)C4O)cc3OC2CO)ccc1O</smiles>

Isosilibina

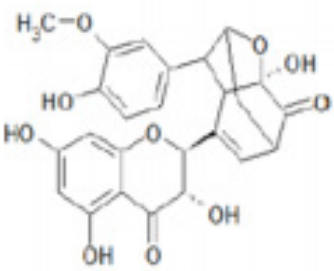

Silidianina

Figure 2: Chemical structures of silymarin constituents.

Source: Sonnenbichler, et al. (1999), adapted by Gonçalves, 2016. 
Thus, the aim of the present study is to present a clinical case, whose treatment of non-alcoholic hepatic steatosis was carried out with the use of silymarin. Studies found in the literature on the subject show that silymarin can be accepted as a safe herbal product, as there are no known health risks or side effects, when there is an adequate administration of projected therapeutic dosages $[13,16,17]$.

\section{Case Report}

KAS, white, male, 52 years old, physiotherapist, married, born and living in Belo Horizonte, in March2020 soughta gastroenterology and bariatric endoscopy clinic in Belo Horizonte, after being referred by the general practitioner who had requested an US of the total abdomen, at the patient's request. This exam showed, as an alteration, Moderate Liver Steatosis. In the anamnesis, the patient had only non-specific complaints such as sporadic abdominal distention, usually postprandial, intermittent dyspepsia, and joint pain in both knees. He also reported gaining around 20 kilos in the last five years, with a current BMI of $32 \mathrm{~kg} / \mathrm{m} 2$ (Weight: $101.3 \mathrm{~kg}$ ). He reports being hypertensive and diabetic (Type 2 diabetes). Directed physical examination revealed a globose abdomen, painless to superficial and deep palpation, and a palpable liver in the costal margin. The patient also reports using antihypertensives and oral hypoglycemic agents. Specific complementary liver function tests (AST, ALT and GGT) were requested to confirm liver involvement, in addition to bilirubin, renal function, coagulogram, fasting glucose and glycated hemoglobin, total cholesterol and fractions, protein dosage, alkaline phosphatase, blood count and liver enzymes.

In the anamnesis, the patient also said that he used alcohol irregularly, in small amounts, also referring to the absence of previous liver disease. He reported tiredness in performing some tasks, possibly referring to the lack of physical exercise. When asked about eating habits, he said he mainly eats foods rich in carbohydrates and does not follow any specific diet to control blood glucose. The tests showed changes in transaminases that came up to 03 times the laboratory reference value. Blood glucose of $142 \mathrm{~g} /$ $\mathrm{dl}$ and glycated hemoglobin of $6.2 \%$. Cholesterol also proved to be $1.5 \mathrm{X}$ above the reference value. It was decided not to request liver biopsy or nuclear magnetic resonance (MRI) at this time, as the patient had no clinical or laboratory changes that would justify such tests, but it was explained to him that these tests might be necessary in the future to confirm the diagnosis of non-alcoholic hepatic steatosis and evaluation of centrilobular fibrosis.

In front of the table, K.A.S. he was instructed and started a treatment with Steaton - 200mg (Dry extract of Silybum marianum - equivalent to $107.7 \mathrm{mg}$ (53.8\%) of silymarin expressed as silybinin), 03 times a day, for 180 days. In addition, the patient was referred to the clinic's nutrition service, where a low-calorie, low-carbohydrate diet was prescribed, both for glycemic control and for weight loss. The possibility of using an intragastric balloon was also raised if the patient was not successful in losing weight with nutritional monitoring. Follow-up was done monthly for 180 days. At the same time, regular exercise and a decrease in alcohol intake were requested. After 06 months of treatment with Steaton and the establishment of healthy habits, new tests were requested, which found the normalization of all tests to the reference values, as shown in the tables below, in addition to the loss of $15 \mathrm{~kg}$ (Current weight: $86 \mathrm{~kg}$ - BMI: $27.1 \mathrm{~kg} / \mathrm{m} 2$ ) [Table 1].

Table 1: Serum and ultrasound liver indices obtained before and after treatment with silymarin and diet (mean \pm SD).

\begin{tabular}{|c|c|c|c|}
\hline Variables & Before & After & P Value \\
\hline Steato Test & $0,71 \pm 0,07$ & $0,40 \pm 0,05$ & $<0,001$ \\
\hline ALT (U/L) & $109,48 \pm 4,4$ & $75,12 \pm 3,3$ & $<0,001$ \\
\hline AST (U/L) & $72,39 \pm 8,4$ & $48,65 \pm 3,2$ & $<0,05$ \\
\hline$\gamma$-GT (IU/L) & $45,51 \pm 1,2$ & $29,33 \pm 1,1$ & $<0,001$ \\
\hline TNF- $\alpha(\mathrm{pg} / \mathrm{mL})$ & $16,2 \pm 0,9$ & $9,7 \pm 0,7$ & $<0,001$ \\
\hline Hepatorenal relationship & $2,5 \pm 0,3$ & $1,8 \pm 0,6$ & $<0,05$ \\
\hline
\end{tabular}

ALT: Alanina aminotransferase; AST: Aspartato aminotransferase; $\gamma-G T$ : Gama glutamil transferase; TNF- $\alpha$ : Tumor necrosis factor. Source: World journal of hepatology - Modified. 2013.

After 06 months, serology for hepatitis (A, B, C, CMV and EBV) were also performed, which were negative. Thus, autoimmune causes were excluded by the negativity of immunological markers performed (antinuclear, antimitochondrial, antismooth muscle, LKM 1 and 2) autoantibodies. Metabolic pathologies were also excluded, namely Wilson's disease, hemochromatosis, and alpha-1 antitrypsin deficit (normal ceruloplasmin, copper, 1 antitrypsin and transferrin saturation measurements). CEA and aFP tumor markers were normal. And the new abdominal ultrasound (after 06 months) was compatible with mild and diffuse hepatic steatosis.
In view of these results and due to the maintenance of the patient's alcohol intake, it was decided to perform a liver biopsy, which showed a pattern of micronodular liver cirrhosis with mild micro and macrovascular steatosis, with minimal inflammatory activity. Thus, the Steaton was maintained, this time twice a day, and the patient was instructed to maintain dietary re-education and suspend the use of alcoholic beverages.

\section{Discussion}

The anti-inflammatory effect of silymarin has already been confirmed in vitro, relating its use to downregulation of the 
expression of cytokine genes (IL-8 and TNF- $\alpha$ ) in hepatocytes, reducing oxidative stress. The explanation of the hepatoprotective effect of silymarin seems to be related to the inhibition of lipid peroxidase formation in hepatocytes and changes in the physical properties of plasma membranes, which would make the hepatocytes more resistant to osmotic lysis [17]. In the case in question, laboratory tests reported improvement in the picture and a decrease in serum levels of liver enzymes, especially ALT., after 06 months of treatment, reinforcing the therapeutic use of silymarin in the treatment of this condition. A randomized study conducted by 15 found results similar to the present case. They selected patients with non-alcoholic hepatic steatosis to verify the use of silymarin in decreasing aminotransferase levels. The experimental group had significant improvements, unlike the placebo, without therapeutic significance. In a two-month period, ALT and AST levels fell from 103.1 to 41.4 and from 53.7 to $29.1 \mathrm{IU} / \mathrm{mL}(\mathrm{P}<0.001)$ in patients who used silymarin, while the decrease of ALT and AST levels was 7.8 and $2.2 \mathrm{IU} / \mathrm{mL}$ in the placebo group.

Also, with results similar to those of the present clinical case, the study by Cacciapuoti $\mathrm{F}$ et al. $16 \mathrm{~A}$ randomized clinical trial produced by Solhi $\mathrm{H}$, et al. [12] found a decrease in mean fasting glucose levels after a restricted diet and treatment with silymarin. The Steato test, in the study by Cacciapuoti F, et al. [16], also showed a significant reduction $(\mathrm{P}<0.001)$ from baseline $(0.71 \pm 0.07)$ at the end of treatment $(0.40 \pm 0.05)$. Serum ALT levels $(\mathrm{P}<0.01)$ fell on average from $109.48 \pm 4.4$ to $75.12 \pm 3.3 \mathrm{U} / \mathrm{L}$. The AST recorded at baseline (72.39 $\pm 8.4 \mathrm{U} / \mathrm{L})$ also dropped considerably $(\mathrm{P}<0.05)$ after silymarin and diet $(48.65 \pm 3.2 \mathrm{U} / \mathrm{L}) . \gamma$-GT levels decreased from $45.51 \pm 1.2$ to $29.33 \pm 1.1$, with a significant difference $(\mathrm{P}<$ $0.001)$. TNF- $\alpha$ dropped from $16.2 \pm 0.9 \mathrm{pg} / \mathrm{mL}$ to $9.7 \pm 0.7$ after the six-month treatment $(\mathrm{P}<0.001)$. Finally, there was also a significant reduction in the hepatorenal ratio, which dropped from $2.5 \pm 0.3$ to $1.8 \pm 0.6(\mathrm{P}<0.05)$.

Solhi H, et al. [12] showed relatively similar means of reduction, also showing a decrease in the mean levels of ALT and AST with the use of silymarin in the treatment of non-alcoholic steatohepatitis. ALT levels ranged from $91.3 \pm 21.3$ to $38.4 \pm 11.8 \mathrm{U} / \mathrm{L}$, in the case group before and after treatment, respectively. In the control group, the mean values were $84.6 \pm 52$ and $33 \pm 29.9 \mathrm{U} / \mathrm{L}$, before and after treatment, respectively. AST levels dropped from $62.8 \pm 10.5$ to 30.5 $\pm 8.2 \mathrm{U} / \mathrm{L}$ in the case group before and after silymarin use. While in the control group, the mean values were from $70.4 \pm 18.9$ to $36.2 \pm$ $12.4 \mathrm{U} / \mathrm{L}$, before and after treatment, respectively [12].

Wah-Kheong Chan, et al. performed the first randomized, double-blind study on the use of silymarin for the treatment of non-alcoholic hepatic steatosis, which used paired liver biopsies and provided histological confirmation of previous observations. Treatment with silymarin for 48 weeks was associated with significantly greater improvement in fibrosis compared to placebo based on histology. It is likely that silymarin has anti-fibrotic properties, as seen in recent clinical trials, acting in the regulation of apoptosis [10]. In another study, which used an established in vitro model of human liver fibrogenesis, silymarin demonstrated direct and indirect antifibrotic properties by reducing the proliferation and migration induced by platelet-derived growth factor, reducing collagen type 117 synthesis. Mosque et al. (2019), in their review of the literature on risk factors associated with non-alcoholic hepatic steatosis, reinforced, as shown in the present study, the importance of associating treatments with changes in lifestyle, regular aerobic exercise and healthy eating. According to Liu X, et al. (2018) patients submitted to a diet rich in red meat and soft drinks were more likely to develop the syndrome, while no significant association was observed in patients with a diet rich in refined grains, fresh fruits and vegetables.

[Vespasiani Gentilucci, et al. (2018), Cruz FJ, et al. (2016), Divella R, et al. (2019), Liu X, et al. (2018)] reinforced, in turn, the fact that obesity is a strong risk factor for non-alcoholic hepatic steatosis. As seen, the patient analyzed in the present case report had this condition. According to Divella, et al. (2019), the prevalence of NAFLD, for example, reaches 50 to $90 \%$ of obese individuals, in addition to being found in $65 \%$ of individuals with grade I-II obesity (BMI $=30-39.9 \mathrm{~kg} / \mathrm{m} 2$ ) and in $85 \%$ of patients with grade III obesity (BMI = 40-59 kg / m2) [6].

\section{Conclusion}

Changes in the world population's lifestyle and eating habits, together with the evolution of NAFLD diagnostic methods, ended up providing an increase in the prevalence of hepatic steatosis. It is known that NAFLD has a high risk of progression to diseases with high morbidity, such as cirrhosis, liver failure and hepatocellular carcinoma. Liver biopsy is still the gold standard for diagnosis, but it is a questionable procedure due to the risk of complications and the emergence of new diagnostic techniques with high sensitivity. NAFLD treatment consists of lifestyle changes and medication use. However, some agents have shown modest improvements in liver function tests and even histological parameters, despite the fact that studies to date have been limited by small samples and short follow-up periods. The most researched natural treatment for liver diseases is silymarin, a safe herbal medicine, devoid of health risks or side effects. This drug has hepatoprotective, anti-inflammatory, antiproliferative, immunomodulatory and anticholesterolemic properties. Finally, studies showed a significant improvement in serum liver, ultrasound and histological parameters after the use of silymarin. Thus, it is possible to conclude that this drug is a good therapeutic option in the treatment of hepatic steatosis.

\section{Acknowledgement}

None.

\section{Conflict of Interest}

No conflict of interest.

\section{References}

1. Navarro VJ, Belle SH, D Amato M, Adfhal N, Brunt EM, et al. (2019) Silymarin in non-cirrhotics with non-alcoholic steatohepatitis: A 
randomized, double-blind, placebo controlled trial. PloS one 14(9): e0221683.

2. Farias LGN, Oliveira AF, Teles HCC, Santana DS, Oliveira SL, et al. (2016) Efeitos da esteatose hepática não alcoólica nas variáveis hemodinâmicas dos vasos do fígado através da dopplerfluxometria. Capa V. 28(18).

3. Younossi ZM, Koenig AB, Abdelatif D, Fazel Y, Henry L, et al. (2016) Global epidemiology of nonalcoholic fatty liver disease-meta-analytic assessment of prevalence, incidence, and outcomes. Hepatology 64(1): 73-84.

4. Santana JT, Mota AVH, Gonzaga YHG, Gomes RMOP, Melo LC, et al. (2021) Perfil metabólico e antropométrico dos pacientes obesos e não obesos portadores de esteatose hepática não alcoólica. Revista Eletrônica Acervo Saúde 13(2): e5525-e.

5. Vespasiani-Gentilucci U, Gallo P, Dell'Unto C, Volpentesta M, AntonelliIncalzi R, et al. (2018) Promoting genetics in non-alcoholic fatty liver disease: Combined risk score through polymorphisms and clinical variables. World J Gastroenterol 24(43): 4835-4845.

6. Mesquita AO, Cardoso EF, Fernandes LG, Souza VM, Rebelo BRR, et al. (2019) Esteatose hepática não alcoólica: uma análise dos seus fatores de risco. RESU - Revista Educação em Saúde V. 7(1).

7. Mendonça TM, Mendonça LM, Noronha VFCM, Mota AVH, Silva Filho RC, et al. (2020) Hiperferritinemia em pacientes com doença hepática gordurosa não alcoólica. Brazilian Journal of Health Review 3(4): 1083310843.

8. Lankarani KB, Ghaffarpasand F, Mahmoodi M, Lotfi M, Zamiri N, et al. (2013) Nonalcoholic fatty liver disease in southern Iran: a population based study. Hepat Mon 13(5): e9248

9. Chalasani N, Younossi Z, Lavine JE, Charlton M, Cusi K, et al. (2018) The diagnosis and management of nonalcoholic fatty liver disease: practice guidance from the American Association for the Study of Liver Diseases. Hepatology 67(1): 328-357.

10. Pedrassa BC, Rocha EL, Kierszenbaum ML, Bormann RL, Torres LR, et al. (2014) Uncommon hepatic tumors: iconographic essay-Part 1. Radiol Bras 47(5): 310-316.

11. Wong VWS, Chan WK, Chitturi S, Chawla Y, Dan YY, et al. (2018) AsiaPacific Working Party on Non-alcoholic Fatty Liver Disease guidelines 2017-part 1: definition, risk factors and assessment. J Gastroenterol Hepatol 33(1): 70-85.

12. Solhi H, Ghahremani R, Kazemifar AM, Yazdi ZH (2014) Silymarin in treatment of non-alcoholic steatohepatitis: A randomized clinical trial. Caspian J Intern Med 5(1): 9-12.

13. Hajagha MA, Ziaei A, Rafiei R (2008) The efficacy of silymarin in decreasing transaminase activities in non-alcoholic fatty liver disease: A randomized controlled clinical trial.

14. Zhong S, Fan Y, Yan Q, Fan X, Wu B, et al. (2017) The therapeutic effect of silymarin in the treatment of nonalcoholic fatty disease: A meta-analysis (PRISMA) of randomized control trials. Medicine 96(49): e9061.

15. Cachia R, Compañó R, Da Costa O (2007) Grasping the potential of online social networks for foresight. Technological Forecasting and Social Change 74(8): 1179-1203.

16. Loguercio C, Andreone P, Brisc C, Brisc MC, Bugianesi E, et al. (2012) Silybin combined with phosphatidylcholine and vitamin $\mathrm{E}$ in patients with nonalcoholic fatty liver disease: a randomized controlled trial. Free Radic Biol Med 52(9): 1658-1665.

17. Cacciapuoti F, Scognamiglio A, Palumbo R, Forte R, Cacciapuoti F (2013) Silymarin in non-alcoholic fatty liver disease. World J Hepatol 5(3): 109113. 